\title{
Aa. Vv., Saintetés, «Ponts/Ponti»
}

\section{Claudia Mansueto}

\section{(2) OpenEdition \\ Journals}

\section{Édition électronique}

URL : http://journals.openedition.org/studifrancesi/5792

DOI : 10.4000/studifrancesi.5792

ISSN : 2427-5856

\section{Éditeur}

Rosenberg \& Sellier

\section{Édition imprimée}

Date de publication : 1 septembre 2011

Pagination : 465-466

ISSN : 0039-2944

\section{Référence électronique}

Claudia Mansueto, « Aa. Vv., Saintetés, «Ponts/Ponti» », Studi Francesi [En ligne], 164 (LV | II) | 2011, mis en ligne le 30 novembre 2015, consulté le 13 janvier 2021. URL : http://journals.openedition.org/ studifrancesi/5792 ; DOI : https://doi.org/10.4000/studifrancesi.5792

\section{Ce document a été généré automatiquement le 13 janvier 2021.}

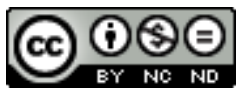

Studi Francesi è distribuita con Licenza Creative Commons Attribuzione - Non commerciale - Non opere derivate 4.0 Internazionale. 


\title{
Aa. Vv., Saintetés, «Ponts/Ponti»
}

\author{
Claudia Mansueto
}

\section{RÉFÉRENCE}

Saintetés, «Ponts/Ponti», n. 9, 2010, 326 pp.

1 Le numéro aborde un thème peu fréquenté par la critique: celui de la représentation de la sainteté dans les textes littéraires. Dédiés aux croyants et aux sceptiques, les articles sont partagés en quatre sections. La première, «Saintetés», est constituée par quatre articles: Saintetés de Liana Nissim (pp. 15-33), Syncrétisme de Saintetés. Saint Monsieur Baly de Williams Sassine de Francesca Paraboschi (pp.35-55), Une voix qui perce le voile: émergence de l'écriture autobiographique dans la relation de 1654 de Marie de l'Incarnation d'Alessandra Ferraro (pp.57-69) et Sainte Philomène du Morne Pichevin de Marco Modenesi (pp. 71-87).

2 L'article de Liana NISSIM analyse trois romans africains francophones où la représentation de la sainteté est particulièrement évidente: Shaba deux (1989) de V.Y. Mudibe qui publie les carnets inédits de Mère Marie Gertrude, témoin littéraire exemplaire de «l'infinie possibilité de l'amour» (p. 18); La nièce de l'Imam (1994) de Mandé Alpha Diarra où Nah Fatima, protagoniste féminine du roman malien, incarne la plus sublime forme de tolérance et d'altruisme et L'initié (1979) du béninois Olympe Bhely-Quenum dont le personnage, Kofi-Marc, est le symbole parfait d'un monde utopique et solitaire où «le bien s'oppose au mal, l'utile s'oppose au nuisible, l'ordre s'oppose au désordre» (p.32). L'article de Francesca PARABOSCHI réfléchit sur le personnage de Monsieur Baly, protagoniste du roman homonyme de Williams Sassine publié en 1973. Exemple d'une sainteté active et déterminée, Monsieur Baly, qui préfère à l'oisif exercice méditatif l'initiative concrète, est, selon Paraboschi, le symbole d'une nouvelle génération africaine qui considère la religion comme un soutien moral nécessaire pour réveiller un continent affaibli par les nombreux mensonges occidentaux. Alessandra FERRARO analyse l'expérience religieuse de l'Ursuline Marie de l'Incarnation, qui, comme Thérèse D'Avila, écrira une passionnante relation sur son 
rapport avec Dieu. Comme le souligne Alessandra Ferraro, ce personnage hermétique est une sorte «de medium à travers lequel s'exprime la voix divine» (p. 65). Combattue entre désirs humains et aspirations divines, déchirée entre doutes et certitudes, Marie Guyart, alias Marie de l'Incarnation, avec son émouvant témoignage conduit, selon Ferraro, «à la naissance de l'autobiographie moderne» (p.69). L'article de Marco MODENESI se penche sur l'œuvre de Raphaël Confiant La Vierge du grand retour (2007). À son avis, pour l'auteur martiniquais le personnage de la prostituée Philomène interprète parfaitement la finalité de toute foi religieuse: aider l'homme «à supporter sa condition dans la vie misérable qu'il est obligé de mener depuis toujours» (p. 74). Apparemment blasphème, Confiant propose au lecteur un mysticisme populaire, non cultivé, où l'absence de méditation est remplacée par un sentiment d'amour presque enfantin.

La deuxième section «Études linguistiques» (pp. 91-121) est entièrement occupée par l'article de Robert CHAUDENSON Saintetés: la langue française où l'auteur s'interroge sur l'existence d'une variété standard de français. Chaudenson souligne la versatilité de la langue, instrument indispensable pour communiquer et traduire les changements historiques et idéologiques et déclare, ironiquement, que toute forme de purisme linguistique est destinée au martyre, «seconde voie d'accès à la sainteté» (p. 120). La troisième section, «Inédits» (pp. 125-130), publie des poèmes de Carole David, écrivaine québécoise qui focalise son activité littéraire surtout sur les problématiques de l'univers féminin. La dernière section, «Notes de lecture» (pp. 133-326), présente un nombre considérable d'ouvrages critiques concernant les différents domaines francophones.

Un numéro monographique, bien organisé, sur un sujet séduisant, éclairé par ces propos de Liana Nissim: «s'il est vrai qu'au sens propre la sainteté n'appartient qu'à Dieu, il est vrai aussi que la sainteté humaine peut présenter une infinité de nuances et de variations» (p. 7). 